\title{
Impacto do aumento da concentração atmosférica de dióxido de carbono sobre a ferrugem e o crescimento do cafeeiro
}

\author{
Fernanda Ribeiro Oliveira Tozzi(1) e Raquel Ghini(2)
}

\begin{abstract}
(1)Universidade Estadual Paulista, Faculdade de Ciências Agrárias, Rua José Barbosa de Barros, no 1780, CEP 18610-307 Botucatu, SP, Brasil. E-mail: oliveira.fernanda@live.com (2)Embrapa Meio Ambiente, Rodovia SP-340, Km 127,5, Tanquinho Velho, CEP $13820-000$ Jaguariúna, SP, Brasil. E-mail: raquel.ghini@embrapa.br
\end{abstract}

\begin{abstract}
Resumo - O objetivo deste trabalho foi avaliar o efeito do aumento da concentração de dióxido de carbono atmosférico sobre o crescimento de plantas e a severidade da ferrugem (causada por Hemileia vastatrix) em cafeeiro (Coffea arabica). Utilizaram-se as cultivares 'Obatã IAC 1669-20' e 'Catuaí Vermelho IAC 144', moderadamente resistente e suscetível à doença, respectivamente. Os tratamentos consistiram de 400 e $508 \mu \mathrm{mol}$ $\mathrm{mol}^{-1}$ de $\mathrm{CO}_{2}$ atmosférico, em dois tipos de estufas de topo aberto (OTC). As plantas das duas cultivares, cultivadas nas OTCs com adição de $\mathrm{CO}_{2}$, apresentaram aumento de área foliar, e da taxa de crescimento em altura e em diâmetro do caule, em comparação às plantas cultivadas em estufas à concentração ambiente de $\mathrm{CO}_{2}$; porém, as cultivares não diferiram quanto ao teor de cera das folhas. Em 'Catuaí Vermelho IAC 144', a severidade da ferrugem diminuiu com o aumento da concentração de $\mathrm{CO}_{2}$, quanto ao número de lesões, área foliar lesionada, número de lesões esporuladas, área lesionada esporulada, percentagem de área foliar lesionada e área abaixo da curva de progresso da doença; no entanto, em 'Obatã IAC 1669-20', a severidade da doença não variou. A incidência de folhas lesionadas por planta, o período latente, a germinação de urediniósporos e a formação de apressórios não são alterados, à dose de $508 \mu \mathrm{mol} \mathrm{mol}^{-1} \mathrm{de} \mathrm{CO}_{2}$, em ambas as cultivares.
\end{abstract}

Termos para indexação: Coffea arabica, Hemileia vastatrix, aquecimento global, $\mathrm{CO}_{2}$, mudanças climáticas.

\section{Impact of increasing atmospheric concentration of carbon dioxide on coffee leaf rust and coffee plant growth}

\begin{abstract}
The objective of this work was to evaluate the effect of increasing the atmospheric concentration of carbon dioxide on plant growth and leaf rust severity (caused by Hemileia vastatrix) on coffee (Coffea arabica). The 'Obatã IAC 1669-20' and 'Catuaí Vermelho IAC 144' cultivars, moderately resistant and susceptible to the disease, respectively, were used. The treatments consisted of 400 and $508 \mu \mathrm{mol} \mathrm{mol}^{-1}$ atmospheric $\mathrm{CO}_{2}$, in two types of open-top chambers (OTC). Plants of the two cultivars, grown in OTCs with addition of $\mathrm{CO}_{2}$, showed increased leaf area, and increased growth rate of height and stem diameter, in comparison with plants in OTCs with ambient $\mathrm{CO}_{2}$ concentration; however, the cultivars did not differ for leaf-wax content. On 'Catuaí Vermelho IAC 144', rust severity reduced at increased $\mathrm{CO}_{2}$ concentration, for number of lesions, lesioned leaf area, number of sporulated lesions, sporulated leaf area, percentage of lesioned area, and area under disease progress curve; however, on 'Obatã IAC 1669-20', the disease severity did not vary. The incidence of lesioned leaves per plant, latent period, urediniospore germinations, and appressorium formation are not changed by the $508 \mu \mathrm{mol} \mathrm{mol}{ }^{-1} \mathrm{CO}_{2}$ dose in both cultivars.
\end{abstract}

Index terms: Coffea arabica, Hemileia vastatrix, global warming, $\mathrm{CO}_{2}$, climate change.

\section{Introdução}

O café é uma das mais importantes commodities do mundo. Em 2013, a área plantada foi de mais de 10 milhões de hectares, em que se produziram 8,9 milhões de toneladas de grãos (FAO, 2016). A produção é realizada principalmente por pequenos agricultores, de regiões tropicais menos desenvolvidas, e os maiores mercados consumidores são o europeu e o norte-americano. Quatro países, em 2013, foram responsáveis por $64,8 \%$ da produção mundial: Brasil $(33,2 \%)$, Vietnam $(16,4 \%)$, Indonésia $(7,8 \%)$ e Colômbia (7,3\%).

$\mathrm{O}$ ambiente determina a produtividade e a qualidade do café, além das práticas de manejo, em razão do efeito direto sobre a ocorrência de insetos-pragas e doenças (Camargo, 2010; Zullo Jr. et al., 2011). Assim, pela importância da cultura, há a necessidade do estudo dos impactos das mudanças climáticas para a elaboração de estratégias de adaptação. Entre as alterações do 
ambiente, a concentração de dióxido de carbono $\left(\mathrm{CO}_{2}\right)$ atmosférico aumentou aproximadamente $40 \%$, desde a Revolução Industrial, e as projeções indicam que esse fenômeno deve continuar até que ocorram reduções substanciais e sustentáveis das emissões desse gás de efeito estufa (Stocker et al., 2013).

As estufas de topo aberto (OTCs, open top chambers) têm sido utilizadas para a avaliação do impacto do aumento da concentração de gases em diversos países (Pritchard \& Amthor, 2005; Lessin \& Ghini, 2009). As OTCs são de formato cilíndrico, com a parede lateral coberta com plástico transparente e o topo aberto, o que permite a interação das plantas com o ambiente externo. $\mathrm{O}$ funcionamento e a instrumentação são semelhantes aos experimentos do tipo Face (free-air carbon dioxide enrichment), em que há a liberação de $\mathrm{CO}_{2}$ em condições de campo. Porém, nas OTCs, há o menor consumo de gás, graças à presença do plástico, o que reduz os custos. As OTCs apresentam, ainda, as vantagens do Face, por serem experimentos instalados em campo e que expõem as plantas às alterações do ambiente.

Os trabalhos sobre os impactos do aumento da concentração de $\mathrm{CO}_{2}$ atmosférico sobre a cultura do café, em geral, abordam efeitos sobre a fisiologia das plantas (Ramalho et al., 2013; Batista, 2015; Ghini et al., 2015; DaMatta et al., 2016), em que aspectos fitossanitários foram pouco estudados. $\mathrm{O} \mathrm{CO}_{2}$ à alta concentração estimula a fotossíntese e o crescimento das plantas. Ramalho et al. (2013) observaram que a assimilação de $\mathrm{CO}_{2}$ pelas plantas de café aumentou de 34 a $49 \%$ em ambiente que continha $700 \mu \mathrm{mol} \mathrm{mol}^{-1} \mathrm{de}$ $\mathrm{CO}_{2}$, em comparação às cultivadas a $380 \mu \mathrm{mol} \mathrm{mol}^{-1}$ de $\mathrm{CO}_{2}$.

Apesar dos benefícios, o aumento da concentração de $\mathrm{CO}_{2}$ acarreta alterações à morfologia e à fisiologia das plantas, que podem modificar os mecanismos de resistência de modo a favorecer a ocorrência de insetos-praga e doenças (Eastburn et al., 2011). Em experimento realizado no sistema Face com $550 \mu \mathrm{mol} \mathrm{mol}{ }^{-1}$ de $\mathrm{CO}_{2}$, houve aumento da taxa fotossintética, aumento da eficiência do uso da água, maior crescimento de plantas e produção de grãos, e a incidência de bicho-mineiro (Leucoptera coffeella) foi reduzida, mas não foi possível verificar os efeitos sobre as doenças, que ocorreram em baixa incidência (Ghini et al., 2015). Em OTCs com $760 \mu \mathrm{mol} \mathrm{mol}{ }^{-1}$ de $\mathrm{CO}_{2}$, instaladas dentro de estufas convencionais e com plantas cultivadas em vasos, cultivares de café responderam ao aumento da concentração de $\mathrm{CO}_{2}$ do ar com o aumento da fotossíntese e das taxas de assimilação de carbono, porém não houve efeitos sobre o crescimento das plantas nem sobre a resposta de resistência à ferrugem (Batista, 2015).

A ferrugem causada pelo fungo Hemileia vastatrix está presente em todas as regiões produtoras e é a principal doença da cultura. Os danos causados pela doença são, principalmente, indiretos, pela indução de desfolha e redução da área fotossinteticamente ativa, o que geralmente torna necessária a aplicação de fungicidas para o controle (Bedendo, 2011). No Brasil, a perda de produção em decorrência da doença varia de 30 a $50 \%$ (Zambolim, 2016). Entre as cultivares mais plantadas no país, a 'Catuaí Vermelho IAC 144' é suscetível à ferrugem, apresenta porte baixo e alta produtividade. A 'Obatã IAC 1669-20' é recomendada para plantios adensados, também é de porte baixo e apresenta moderada resistência (resistência quantitativa parcial) à ferrugem (Fazuoli et al., 2000; Zambolim, 2016).

O objetivo deste trabalho foi avaliar o efeito do aumento da concentração de $\mathrm{CO}_{2}$ atmosférico sobre o crescimento de plantas e a severidade da ferrugem, em duas cultivares de cafeeiro, uma moderadamente resistente à doença e outra suscetível, em estufas de topo aberto.

\section{Material e Métodos}

O experimento foi realizado na Embrapa Meio Ambiente, em Jaguariúna, $\mathrm{SP}\left(22^{\circ} 37^{\prime} \mathrm{S}, 46^{\circ} \mathrm{W}\right.$, à altitude de $570 \mathrm{~m}$ ), em clima subtropical úmido, com estação chuvosa no verão e seca no inverno - $\mathrm{Cfa}$, conforme a classificação de Köppen-Geiger. A temperatura anual média é de $20^{\circ} \mathrm{C}$, e a precipitação, de $1.343 \mathrm{~mm}$ por ano (Alvares et al., 2013). O solo é do tipo Latossolo Vermelho de textura argilosa.

Dois conjuntos de OTCs foram utilizados, o primeiro foi construído conforme Pritchard \& Amthor (2005), e o segundo, conforme versão modificada de Ghini et al. (2014). Cada um desses conjuntos foi composto por seis OTCs, das quais três receberam aplicação de $\mathrm{CO}_{2}$, e as outras três permaneceram com a concentração ambiente de $\mathrm{CO}_{2}$ do ar.

As diferenças entre os conjuntos de OTCs referem-se à altura das estufas e ao tipo de instrumentação 
utilizado para automação da aplicação de $\mathrm{CO}_{2}$. A versão inicial de OTC apresentava uma base circular com 1,9 m de diâmetro e $2 \mathrm{~m}$ de altura, com uma redução da abertura no topo. A lateral foi coberta por filme de polietileno transparente tratado contra raios ultravioleta. Apresentava uma camada dupla do plástico na base, com orifícios na camada interior, por onde o ar enriquecido com o $\mathrm{CO}_{2}$ era liberado. $\mathrm{O} \mathrm{CO}_{2}$ foi armazenado em cilindros pressurizados, dotados de manômetro e fluxômetro, de forma a regular a vazão do gás. $\mathrm{O} \mathrm{CO}_{2}$ puro, proveniente do cilindro, foi conduzido às OTCs por meio de canalização subterrânea e injetado contra um ventilador acoplado à estufa, de modo a proporcionar a mistura do ar com o $\mathrm{CO}_{2}$, para homogeneizar a concentração do gás no interior da estufa. OTCs semelhantes às descritas, sem a injeção de $\mathrm{CO}_{2}$, foram utilizadas para comparações com a concentração atmosférica local. $\mathrm{O}$ monitoramento da concentração de $\mathrm{CO}_{2}$ foi realizado a intervalos de $5 \mathrm{~min}$, com auxílio de um analisador de gás por infravermelho GMM 222 (IRGA, Vaisala, Vantaa, Finlândia), em medições de 0 a $2.000 \mu \mathrm{mol}$ $\mathrm{mol}^{-1}$, localizado no centro de uma parcela (OTC) de cada tratamento.

As OTCs modificadas diferiram das anteriores pois tinham um metro de altura, não tinham ventilador, e o $\mathrm{CO}_{2}$ puro era liberado por duas canalizações perfuradas a cada três centímetros e dispostas na lateral interna da estufa a 30 e $60 \mathrm{~cm}$ do solo. O monitoramento da concentração do gás também foi realizado por meio de um IRGA, que forneceu as informações por rede sem fio para controladores de fluxo que regularam a liberação do gás, conforme a concentração do $\mathrm{CO}_{2}$ nas estufas e a intensidade do vento. Uma estação meteorológica automática WXT520 (Vaisala, Vantaa, Finlândia) fez parte da instrumentação dos experimentos, e continha um anemômetro ultrassônico, além de sensores de temperatura e umidade do ar.

$\mathrm{O}$ experimento foi realizado em arranjo fatorial $2 \times 2$ (duas concentrações de $\mathrm{CO}_{2}$ e duas cultivares) com tratamentos em blocos ao acaso. $\mathrm{O}$ experimento foi repetido quatro vezes, duas no conjunto de OTCs construído conforme Pritchard \& Amthor (2005) e duas no conjunto de OTCs modificadas. Cada OTC foi considerada uma parcela experimental. Assim, cada conjunto de OTCs foi composto por seis parcelas (OTCs), das quais três foram mantidas na condição ambiente e três foram enriquecidas com $\mathrm{CO}_{2}$, no total de três blocos por conjunto de OTCs. A concentração média de $\mathrm{CO}_{2}$ foi de $508 \mu \mathrm{mol} \mathrm{mol}{ }^{-1}$ no tratamento com adição de $\mathrm{CO}_{2}$, e de $400 \mu \mathrm{mol} \mathrm{mol}^{-1}$ em estufas em concentração ambiente.

Mudas da cultivar 'Catuaí Vermelho IAC 144', suscetível à ferrugem, e da cultivar moderadamente resistente 'Obatã IAC 1669-20', com média de quatro pares de folhas definitivas, foram obtidas de um viveiro comercial. Em cada OTC (com e sem injeção de $\mathrm{CO}_{2}$ ), 20 mudas (10 de 'Catuaí Vermelho IAC 144' e 10 de 'Obatã IAC 1669-20') foram transplantadas de tubetes diretamente no solo. O espaçamento utilizado foi de $30 \times 30 \mathrm{~cm}$, e a disposição das cultivares nas parcelas foi aleatorizada.

Como adubação, cada parcela recebeu $2,5 \mathrm{~kg}$ de composto ( $1 \%$ de N, $15 \%$ de C), $48 \mathrm{~g}$ de $\mathrm{KCl}, 375 \mathrm{~g}$ de superfosfato simples, $96 \mathrm{~g}$ de termofosfato $(17,5 \% \mathrm{de}$ $\mathrm{P}_{2} \mathrm{O}_{5}, 18 \%$ de $\mathrm{Ca}, 7 \%$ de $\mathrm{Mg}, 0,1 \%$ de $\mathrm{B}, 0,05 \%$ de $\mathrm{Cu}$, $0,3 \%$ de $\mathrm{Mn}, 10 \%$ de Si e $0,05 \%$ de $\mathrm{Zn}$ ) e $100 \mathrm{~g}$ de ureia. Como adubação de cobertura, aplicou-se uma solução de ureia a $2 \%$ de N, a cada dois meses. A irrigação foi feita por gotejamento e com frequência, de acordo com a necessidade hídrica das plantas. O manejo de plantas daninhas foi realizado periodicamente por meio de capina manual.

A altura das plantas foi obtida com auxílio de uma régua, tendo-se medido as plantas do colo até o meristema apical do ramo ortotrópico, a intervalos mensais, por aproximadamente 8 meses. $\mathrm{O}$ diâmetro do caule foi medido com a mesma frequência, na região do colo da planta, com auxílio de um paquímetro digital. As taxas de crescimento em altura e diâmetro do colo das plantas foram obtidas pelo cálculo da diferença entre os dados da última avaliação e os iniciais (primeira medição), dividida pelo número de dias de duração de cada repetição do ensaio.

Para a quantificação de cera epicuticular (modificado de Hamilton, 1995), utilizou-se um par de folhas de três plantas de cada cultivar, por parcela. Cada folha foi lavada duas vezes, com $10 \mathrm{~mL}$ de clorofórmio, em placa de Petri, tendo-se agitado cuidadosamente durante $10 \mathrm{~s}$. Os extratos obtidos foram filtrados (em filtro de papel comum, previamente lavado com clorofórmio), acondicionados em recipiente de peso conhecido e expostos à evaporação à temperatura ambiente, em capela de exaustão. As amostras foram mantidas em dessecador com sílica e pesadas até certificação de massa de matéria seca constante. Os valores foram 
expressos como quantidade de cera por unidade de área foliar $\left(\mu \mathrm{g} \mathrm{cm}^{-2}\right)$ e, para tanto, a área foliar foi calculada, por meio do Assess 2.0 (American Phytopathological Society, St. Paul, MN, EUA).

Quando as plantas atingiram de quatro a seis pares de folhas, que cresceram sob efeito dos tratamentos, selecionaram-se folhas novas, totalmente distendidas para inocular-lhes o patógeno. Assim, o segundo e o terceiro par de folhas do ramo ortotrópico (a partir do ápice) foram infectados com uma suspensão de urediniósporos de $H$. vastatrix, no total de 40 folhas por parcela de cada cultivar.

O inóculo foi coletado na variedade Harar, com predominância da raça II do patógeno, no Instituto Agronômico (IAC), Campinas, SP. A suspensão foi preparada com a adição de $1 \mathrm{mg}$ de urediniósporos para cada mililitro de água destilada, com $0,05 \%$ de tensoativo hidrolítico Tween 20. Após agitação por 10 min em agitador magnético, a suspensão foi calibrada em câmara de Neubauer para a concentração de $1,5 \times 10^{5}$ urediniósporos $\mathrm{mL}^{-1}$. Parte do preparado foi reservada para verificação da viabilidade dos urediniósporos. Para tanto, adicionaram-se três gotas da suspensão por lâmina, em quatro lâminas, que foram mantidas em câmara úmida e escura por 24 horas. A percentagem de germinação foi determinada por observação de 16 campos em microscópio óptico ( $250 \mathrm{X})$, tendo-se considerado o fungo como germinado, quando o tubo germinativo foi maior do que o menor comprimento do urediniósporo. A viabilidade encontrada variou entre 55 e 75\% nas diferentes inoculações.

A inoculação foi feita pela pulverização da suspensão à parte abaxial das folhas selecionadas, em condições de baixa luminosidade (final do dia). Em seguida, as parcelas foram cobertas com plástico escuro, borrifados com água, e o solo foi irrigado, para garantir a manutenção das plantas em câmara úmida e a ausência de luz por 12 horas.

Após o aparecimento dos sintomas, a face abaxial das folhas foi fotografada a cada três dias. Posteriormente, as imagens foram analisadas pelo programa Assess 2.0, tendo-se obtido a área foliar, o número de lesões e o número de lesões com urediniósporos (lesões esporuladas). Os valores foram expressos pela quantidade de doença por unidade de área foliar. Com os resultados do número de lesões, obtidos nas avaliações periódicas, calculou-se a área abaixo da curva de progresso da doença (AACPD). Com a quantificação periódica do número de lesões e do número de lesões esporuladas, calculou-se o período latente, obtido pelo número de dias entre a inoculação e a presença de $50 \%$ de lesões que apresentavam esporulação.

O efeito do $\mathrm{CO}_{2}$ sobre a germinação de $H$. vastatrix foi avaliado em três folhas do quarto par (a partir do ápice), coletadas de cada cultivar das parcelas testemunhas, ou seja, que foram cultivadas sem adição de $\mathrm{CO}_{2}$. Após a inoculação do patógeno, de forma semelhante ao realizado para avaliar a doença, as folhas permaneceram oito horas em câmara úmida e no escuro, em OTC com ou sem injeção de $\mathrm{CO}_{2}$, para verificar o efeito direto do gás sobre o patógeno. Para visualização das estruturas do patógeno, fez-se a impressão da folha em lâmina de microscopia, que continha uma gota de cola de secagem rápida. Os urediniósporos foram corados em safranina para posterior contagem do número de germinados e de apressórios, formados em três campos de 100 urediniósporos. Considerou-se como germinado o urediniósporo com tubo germinativo maior do que o menor comprimento do urediniósporo.

A análise de variância foi feita, e as médias foram comparadas pelo teste de Tukey, a $5 \%$ de probabilidade. Para a análise, os dados de número, área de lesões e esporulação foram transformados a $\log (x+1)$, e a percentagem de área lesionada e de germinação foram transformadas em raiz quadrada de x. O programa estatístico utilizado foi o Minitab, versão 16 (Minitab Inc., State College, PA, EUA). Os dados das quatro repetições do experimento foram analisados em conjunto, em razão da distribuição normal e homogeneidade de variância.

\section{Resultados e Discussão}

$\mathrm{O}$ aumento da concentração de $\mathrm{CO}_{2}$ do ar resultou em incremento da biomassa das mudas de cafeeiro (Figura 1). As duas cultivares apresentaram maior área foliar e taxa de crescimento em altura e em diâmetro do caule, quando cultivadas em ambiente com adição de $\mathrm{CO}_{2}$. $\mathrm{O}$ aumento do desenvolvimento de plantas foi observado por outros autores e é resultante do estímulo à fotossíntese (Ramalho et al., 2013; Ghini et al., 2015; DaMatta et al., 2016). Carvalho et al. (2010) relataram que há correlação positiva entre altura de plantas, diâmetro do caule e produtividade do café, o que ressalta a importância de estudos que abordem o efeito do aumento do $\mathrm{CO}_{2}$ do ar na cultura. 
A quantidade de cera epicuticular não apresentou diferenças quanto às cultivares e à concentração do gás (Figura 1). A cera confere ao vegetal uma barreira protetora a alterações adversas do ambiente, maior resistência à perda de água e a certas doenças e é sensível a alterações ambientais (Shepherd \& Griffiths, 2006). A camada de cera é importante para evitar o desenvolvimento da doença, pois pode tornar a superfície da planta hidrofóbica, o que dificulta a formação de filme de água e, consequentemente, $\mathrm{o}$ processo de germinação do fungo. $\mathrm{O}$ efeito do aumento da concentração atmosférica de $\mathrm{CO}_{2}$ sobre a quantidade e composição da cera epicuticular é controverso (Shepherd \& Griffiths, 2006). Prior et al. (1997) também não observaram efeito do $\mathrm{CO}_{2}$ sobre a quantidade de cera em Pinus palustris. Entretanto, a quantidade de cera foliar aumentou em Betula pubescens cultivada em ambiente enriquecido com
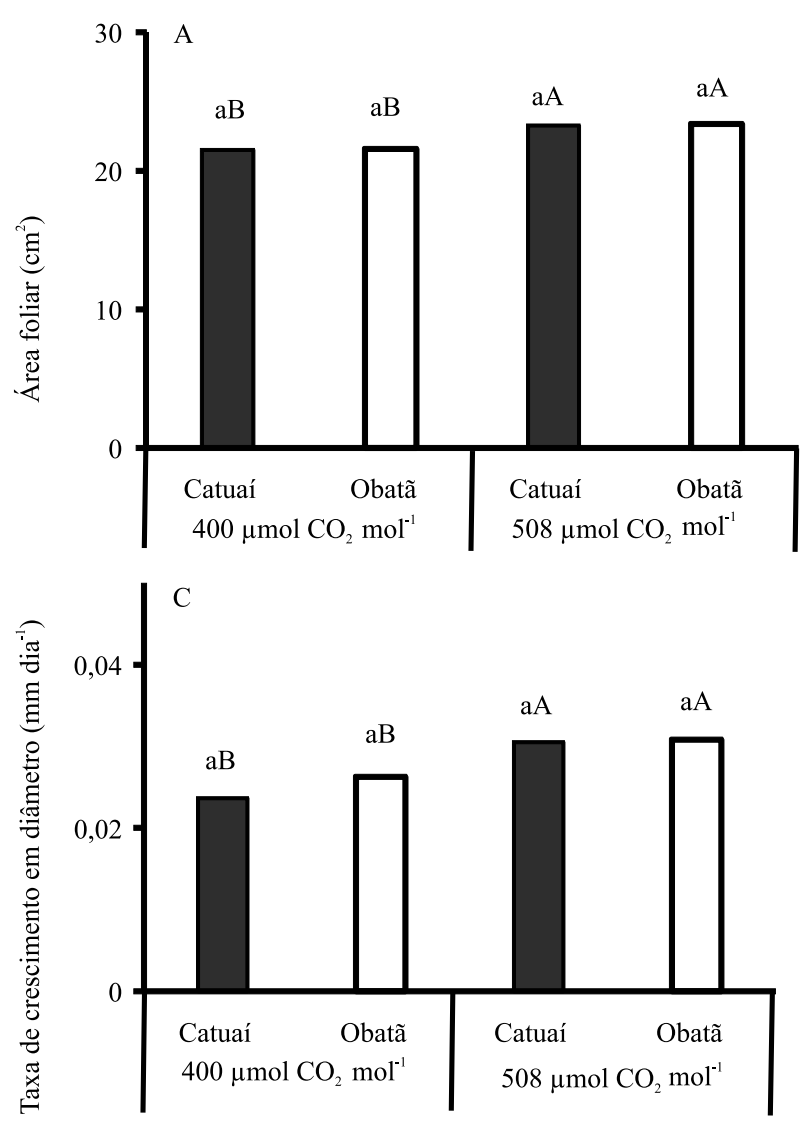

$\mathrm{CO}_{2}$ e $\mathrm{CO}_{2}+\mathrm{O}_{3}$ (Vanhatalo et al., 2001). Quantidades maiores de cera foram observadas apenas em concentração de $\mathrm{CO}_{2}$ acima de $750 \mu \mathrm{mol} \mathrm{mol}^{-1}$, o que indica que, a concentrações menores do gás, a variação natural da cera epicuticular mascara os efeitos positivos do $\mathrm{CO}_{2}$ (Paoletti et al.,1998).

Quanto ao comportamento da doença, a severidade da ferrugem foi menor em consequência do aumento da concentração de $\mathrm{CO}_{2}$ para a cultivar 'Catuaí Vermelho IAC 144', suscetível à doença (Figura 2). Na 'Obatã IAC 1669-20', moderadamente resistente à ferrugem, a adição do gás não teve efeito sobre a doença. Plantas de 'Catuaí Vermelho IAC 144', cultivadas em ambiente com maior concentração de $\mathrm{CO}_{2}$, tiveram redução do número de lesões (44\%) e de área lesionada (39\%), por unidade de área foliar. $\mathrm{O}$ mesmo fato foi observado quanto ao número de lesões esporuladas e área lesionada esporulada. A percentagem de área lesionada
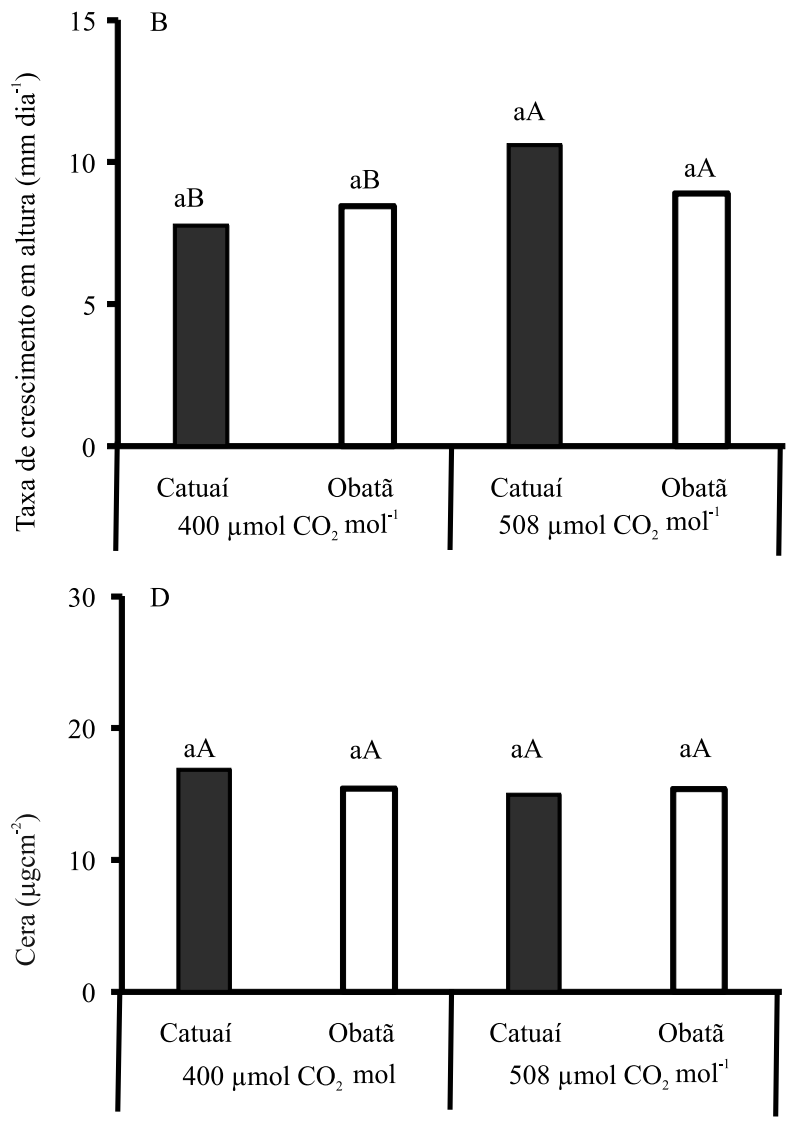

Figura 1. Área foliar (A), taxa de crescimento em altura (B) e em diâmetro do colo da planta (C), e quantidade de cera epicuticular (D) de cafeeiros 'Catuaí Vermelho IAC 144' e 'Obatã IAC1669-20', cultivados em estufas de topo aberto com injeção de $\mathrm{CO}_{2}\left(508 \mu \mathrm{mol} \mathrm{mol}^{-1}\right)$ ou sem injeção de $\mathrm{CO}_{2}\left(400 \mu \mathrm{mol} \mathrm{mol}^{-1}\right)$. Médias com letras iguais, minúsculas (concentrações de $\mathrm{CO}_{2}$ ) e maiúsculas (cultivares), não diferem pelo teste de Tukey, a 5\% de probabilidade. Para a análise, os dados foram transformados em $\log (\mathrm{x}+1)$. 

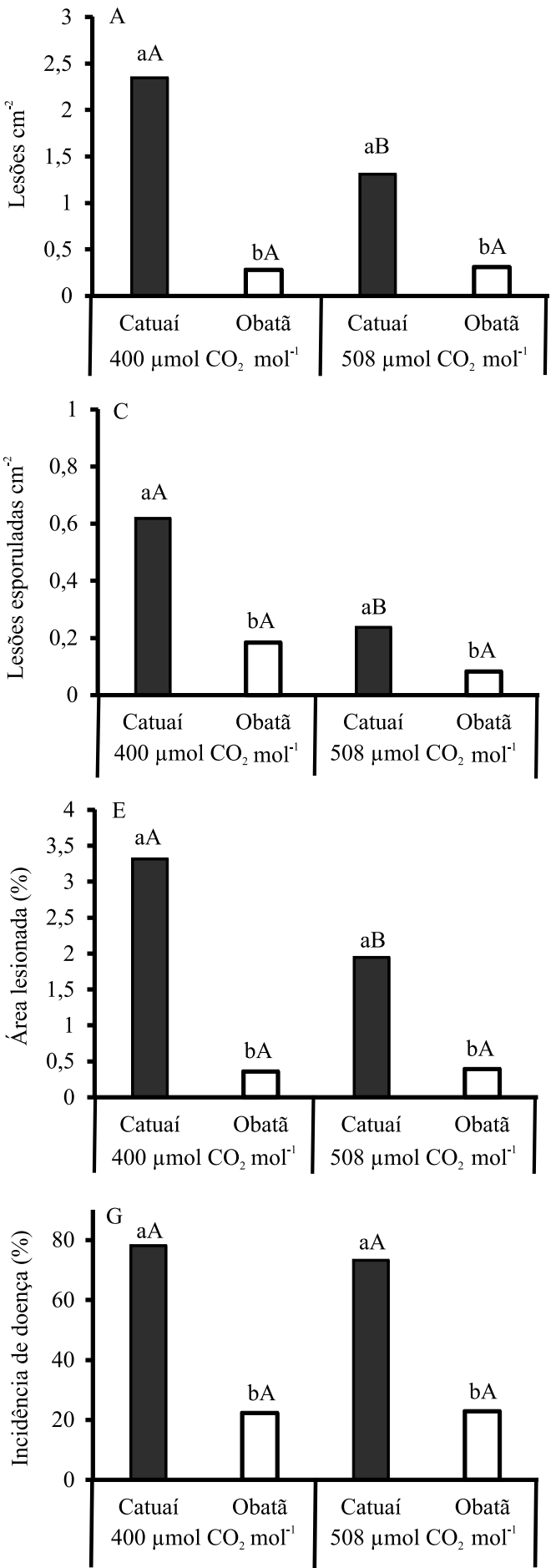
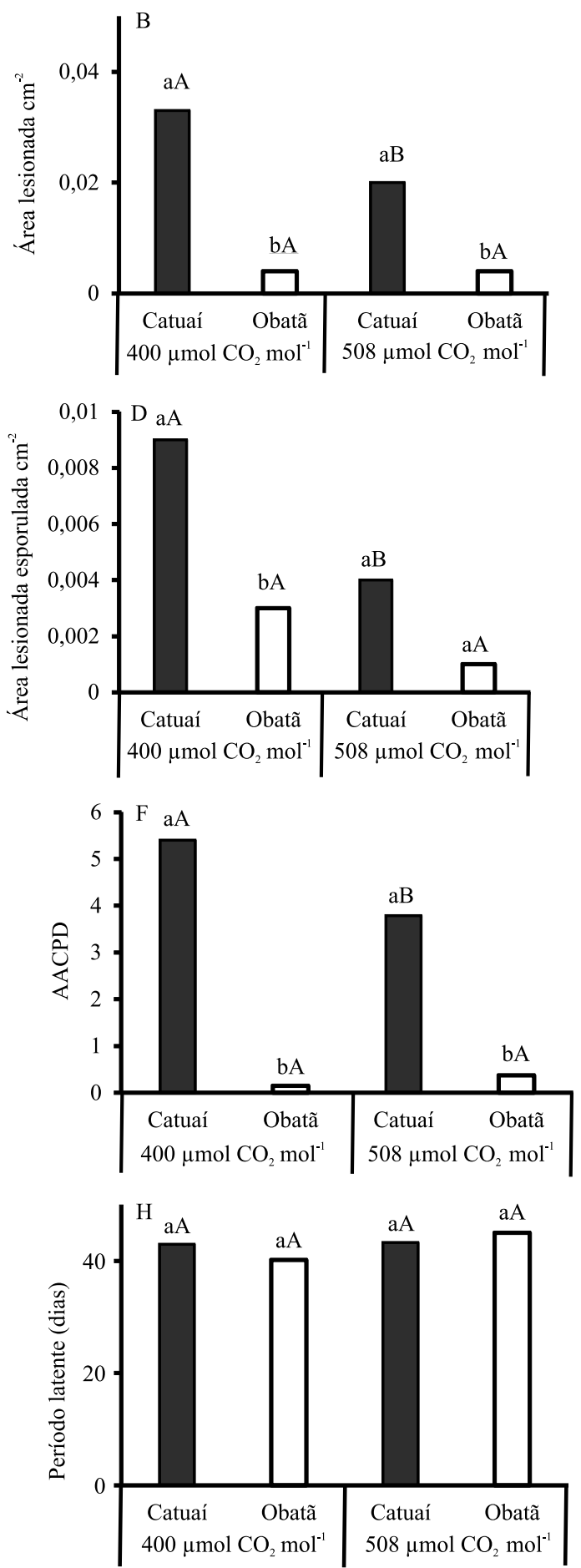

Figura 2. Número de lesões (A), área lesionada (B), número de lesões esporuladas (C), área lesionada esporulada (D), percentagem de área lesionada (E), área abaixo da curva de progresso da severidade da doença (AACPD) (F), incidência de folhas lesionadas por planta $(\mathrm{G})$ e período latente $(\mathrm{H})$ da ferrugem do cafeeiro, em plantas de 'Catuaí Vermelho IAC 144' e 'Obatã IAC1669-20' cultivadas em estufas de topo aberto, com injeção de $\mathrm{CO}_{2}\left(508 \mu \mathrm{mol} \mathrm{mol}^{-1}\right)$ ou sem injeção de $\mathrm{CO}_{2}$ $\left(400 \mu \mathrm{mol} \mathrm{mol}^{-1}\right)$. Médias com letras iguais, minúsculas (concentrações de $\mathrm{CO}_{2}$ ) e maiúsculas (cultivares), não diferem pelo teste de Tukey, a $5 \%$ de probabilidade. Para a análise, com exceção do período latente, os dados foram transformados em $\log (\mathrm{x}+1)$ ou raiz quadrada de $\mathrm{x}$ (em caso de percentagem). 
e a AACPD também foram reduzidas em consequência do gás. A severidade da doença foi sempre menor na cultivar 'Obatã IAC 1669-20', que apresenta resistência moderada à ferrugem, do que na 'Catuaí Vermelho IAC 144'. Apesar de a severidade da doença ter sido baixa em todos os tratamentos, a incidência foi alta na cultivar suscetível. No entanto, só houve diferença significativa entre as cultivares. O período latente não diferiu entre os tratamentos.

As percentagens de germinação e de formação do apressório do patógeno não foram alteradas em consequência do $\mathrm{CO}_{2}$, o que é indicativo de que a redução da severidade da doença não foi provocada pelo efeito direto sobre a germinação do patógeno (Figura 3).

Um dos mecanismos responsáveis pela redução da severidade da doença, com o aumento da concentração de $\mathrm{CO}_{2}$, é a redução da condutividade estomatal (Riikonen et al., 2008), o que afeta diretamente os componentes epidemiológicos de diversas doenças, inclusive a ferrugem-do-cafeeiro, pois resulta em restrição da penetração de patógenos. $\mathrm{O}$ aumento do $\mathrm{CO}_{2}$ pode também alterar a resposta de defesa da planta a patógenos, como a maior produção de fitoalexinas, observada em soja cultivada em ambiente com $720 \mu \mathrm{mol} \mathrm{mol}^{-1}$ de $\mathrm{CO}_{2}$, em comparação à concentração ambiente (Braga et al., 2006).

$\mathrm{O}$ aumento da biomassa e a redução da severidade da ferrugem, promovidas pelo aumento da concentração de $\mathrm{CO}_{2}$ atmosférico, podem compensar efeitos negativos de outras variáveis do ambiente, que serão alteradas com as mudanças climáticas. Martins et al. (2014) avaliaram o efeito combinado do aumento da concentração de $\mathrm{CO}_{2}$ e da temperatura e verificaram que, apesar das mudanças promovidas pelos dois fatores do ambiente, a maioria dos nutrientes foi mantida dentro de uma faixa considerada adequada, o que indica que a planta pode manter balanços minerais satisfatórios nos cenários climáticos futuros. Entretanto, em experimento do tipo Face, verificou-se que, em cafeeiros cultivados em atmosfera enriquecida com $\mathrm{CO}_{2}$, o teor de $\mathrm{P}$ disponível no solo é o que mais se reduz, e isto é indicativo da necessidade de reposição adequada deste nutriente (Maluf et al., 2015).

Os patógenos poderão ser beneficiados pelas mudanças climáticas, uma vez que a habilidade de adaptação a novas condições do ambiente será maior do a que de seus hospedeiros, com ciclos longos de vida, e serão capazes de migrar para locais com clima mais adequado à sobrevivência e à reprodução em um ritmo mais acelerado também (Sturrock et al., 2011). Simulações com temperaturas máximas e mínimas para os cenários futuros preveem a diminuição do período de incubação para a ferrugem do cafeeiro (Ghini et al., 2011) e, portanto, epidemias mais severas, tendência que pode ser neutralizada pelo efeito de redução da doença, em razão do aumento da concentração de $\mathrm{CO}_{2}$, observado no presente trabalho. Considerandose a favorabilidade térmica e hídrica para a ocorrência da ferrugem do cafeeiro, há também a previsão de um decréscimo de épocas favoráveis à doença, em consequência do aumento da temperatura e diminuição da umidade relativa do ar (Pozza \& Alves, 2008).
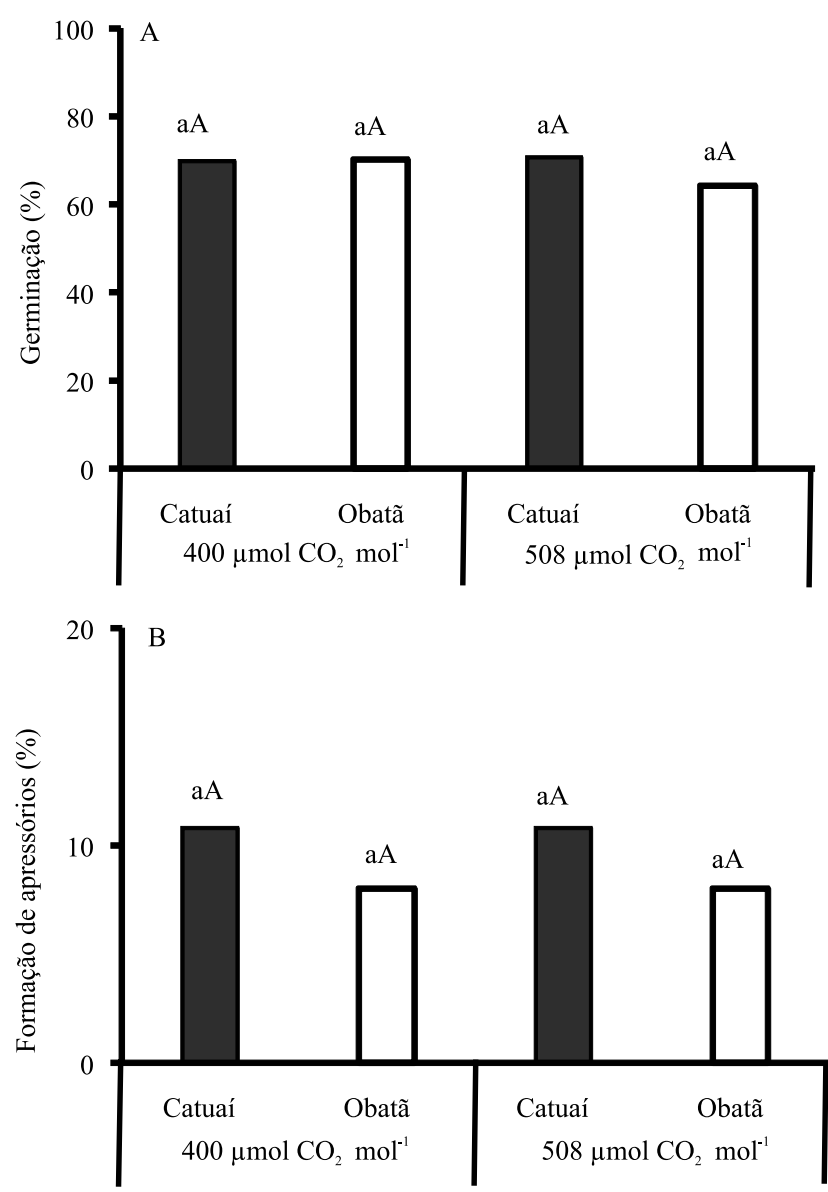

Figura 3. Percentagem de germinação de urediniósporos (A) e formação de apressório (B), em cafeeiros 'Catuaí Vermelho IAC 144' e 'Obatã IAC 1669-20' cultivados em estufas de topo aberto, com injeção de $\mathrm{CO}_{2}\left(508 \mu \mathrm{mol} \mathrm{mol}^{-1}\right)$ ou sem injeção de $\mathrm{CO}_{2}\left(400 \mu \mathrm{mol} \mathrm{mol}^{-1}\right)$. Médias com letras iguais, minúsculas (concentrações de $\mathrm{CO}_{2}$ ) e maiúsculas (cultivares), não diferem pelo teste de Tukey, a 5\% de probabilidade. Para a análise, os dados foram transformados em $\log (\mathrm{x}+1)$ ou raiz quadrada de $\mathrm{x}$ (quando percentagem). 


\section{Conclusões}

1. O aumento da concentração de $\mathrm{CO}_{2}$ da atmosfera promove maior área foliar e taxa de crescimento em altura e em diâmetro, em mudas de cafeeiro das cultivares 'Catuaí Vermelho IAC 144' e 'Obatã IAC 1669-20'.

2. Com o aumento da concentração de $\mathrm{CO}_{2}$ do ar atmosférico, o número de lesões de ferrugem, a área lesionada, o número de lesões esporuladas, a área lesionada esporulada, a percentagem de área lesionada, a área abaixo da curva de progresso da doença e a incidência de folhas lesionadas por planta diminuem, em mudas da cultivar suscetível 'Catuaí Vermelho IAC 144', mas não são alteradas na cultivar moderadamente resistente 'Obatã IAC 1669-20'.

\section{Agradecimentos}

Ao Conselho Nacional de Desenvolvimento Científico e Tecnológico (CNPq, Processo 304189/2013-8), por concessão de bolsa.

\section{Referências}

ALVARES, C.A.; STAPE, J.L.; SENTELHAS, P.C.; GONCALVES, J.L. de M.; SPAROVEK, G. Köppen's climate classification map for Brazil. Meteorologische Zeitschrift, v.22, p.711-728, 2013. DOI: 10.1127/0941-2948/2013/0507.

BATISTA, E.R. Respostas fisiológicas e metabólicas de duas cultivares de Coffea arabica $\mathrm{L}$. submetidas a atmosferas enriquecidas em $\mathrm{CO}_{2}$ em câmaras de topo aberto e sistema FACE. 2015. 142p. Tese (Doutorado) - Instituto de Botânica da Secretaria de Estado do Meio Ambiente, São Paulo.

BEDENDO, I. Ferrugens. In: AMORIM, L.; REZENDE, J.A.M.; BERGAMIN FILHO, A. Manual de fitopatologia: princípios e conceitos. 4.ed. Piracicaba: Agronômica Ceres, 2011. p.479-484.

BRAGA, M.R.; AIDAR, M.P.M.; MARABESI, M.A.; GODOY, J.R.L. de. Effects of elevated $\mathrm{CO}_{2}$ on the phytoalexin production of two soybean cultivars differing in the resistance to stem canker disease. Environmental and Experimental Botany, v.58, p.85-92, 2006. DOI: 10.1016/j.envexpbot.2005.06.018.

CAMARGO, M.B.P. de. The impact of climatic variability and climate change on arabic coffee crop in Brazil. Bragantia, v.69, p.239-247, 2010. DOI: 10.1590/S0006-87052010000100030.

CARVALHO, A.M. de; MENDES, A.N.G.; CARVALHO, G.R.; BOTELHO, C.E.; GONÇALVES, F.M.A.; FERREIRA, A.D. Correlação entre crescimento e produtividade de cultivares de café em diferentes regiões de Minas Gerais, Brasil. Pesquisa Agropecuária Brasileira, v.45, p.269-275, 2010. DOI: 10.1590/ S0100-204X2010000300006.

DAMATTA, F.M.; GODOY, A.G.; MENEZES-SILVA, P.E.; MARTINS, S.C.V.; SANGLARD, L.M.V.P.; MORAIS, L.E.;
TORRE-NETO, A.; GHINI, R. Sustained enhancement of photosynthesis in coffee trees grown under free-air $\mathrm{CO}_{2}$ enrichment conditions: disentangling the contributions of stomatal, mesophyll, and biochemical limitations. Journal of Experimental Botany, v.67, p.341-352, 2016. DOI: 10.1093/jxb/erv463.

EASTBURN, D.M.; MCELRONE, A.J.; BILGIN, D.D. Influence of atmospheric and climatic change on plant-pathogen interactions. Plant Pathology, v.60, p.54-69, 2011. DOI: 10.1111/j.1365-3059. 2010.02402.x.

FAZUOLI, L.C.; MEDINA FILHO, H.P.; GUERREIRO FILHO, O.; GONÇALVES, W; SILVAROLlA, M.B.; GALlO, P.B. Cultivares de café selecionadas pelo Instituto Agronômico de Campinas. In: SIMPÓSIO DE PESQUISA DOS CAFÉS DO BRASIL, 1., 2000, Poços de Caldas. Anais. Brasília: Embrapa Café, 2000. p.488-493.

FAO. FOOD AND AGRICULTURE ORGANIZATION OF THE UNITED NATIONS. FAOSTAT. Disponível em: <http://faostat3. fao.org/download/Q/QC/E>. Acesso em: 4 mar. 2016.

GHINI, R.; HAMADA, E.; PEDRO JÚNIOR, M.J.; GONÇALVES, R.R. do V. Incubation period of Hemileia vastatrix in coffee plants in Brazil simulated under climate change. Summa Phytopathologica, v.37, p.85-93, 2011. DOI: 10.1590/S0100-54052011000200001.

GHINI, R.; MAC LEOD, R.E. de O.; TORRE NETO, A.; CARDOSO, D. C.; BETTIOL, W.; MORAIS, L.A.S. de; VIQUE, B. Increased atmospheric carbon dioxide concentration: effects on eucalypt rust (Puccinia psidii), C:N ratio and essential oils in eucalypt clonal plantlets. Forest Pathology, v.44, p.409-416, 2014. DOI: $10.1111 /$ efp. 12117 .

GHINI, R.; TORRE-NETO, A.; DENTZIEN, A.F.M.; GUERREIRO-FILHO, O.; IOST, R.; PATRÍCIO, F.R.A.; PRADO, J.S.M.; THOMAZIELLO, R.A.; BETTIOL, W.; DAMATTA, F.M. Coffee growth, pest and yield responses to free-air $\mathrm{CO}_{2}$ enrichment. Climatic Change, v.132, p.307-320, 2015. DOI: 10.1007/s10584-015-1422-2.

HAMILTON, R.J. Waxes: chemistry, molecular biology and functions. Edinburgh: Oily Press, 1995. 149p.

LESSIN, R.C.; GHINI, R. Efeito do aumento da concentração de $\mathrm{CO}_{2}$ atmosférico sobre o oídio e o crescimento de plantas de soja. Tropical Plant Pathology, v.34, p.385-392, 2009. DOI: 10.1590/ S1982-56762009000600004.

MALUF, H.J.G.M.; GHINI, R.; MELO, L.B.B. de; SILVA, C.A. Fertilidade do solo e estado nutricional do cafeeiro cultivado em atmosfera enriquecida com $\mathrm{CO}_{2}$. Pesquisa Agropecuária Brasileira, v.50, p.1087-1096, 2015. DOI: 10.1590/S0100$204 X 2015001100012$.

MARTINS, L.D.; TOMAZ, M.A.; LIDON, F.C.; DAMATTA, F.M.; RAMALHO, J.C. Combined effects of elevated $\left[\mathrm{CO}_{2}\right]$ and high temperature on leaf mineral balance in Coffea spp. plants. Climatic Change, v.126, p.365-379, 2014. DOI: 10.1007/ s10584-014-1236-7.

PAOLETTI, E.; NOURRISSON, G.; GARREC, J.P.; RASCHI, A. Modifications of the leaf surface structures of Quercus ilex L. in open, naturally $\mathrm{CO}_{2}$-enriched environments. Plant, Cell and Environment, v.21, p.1071-1075, 1998. DOI: 10.1046/j.1365-30 40.1998.00358.x. 
POZZA, E.A.; ALVES, M.de C. Impacto potencial das mudanças climáticas sobre as doenças fúngicas do cafeeiro no Brasil. In: GHINI, R.; HAMADA, E. (Ed.). Mudanças climáticas: impactos sobre doenças de plantas no Brasil. Brasília: Embrapa Informação Tecnológica, 2008. p.216-233.

PRIOR, S.A.; PRITCHARD, S.G.; RUNION, G.B.; ROGERS, H.H.; MITCHELL, R.J. Influence of atmospheric $\mathrm{CO}_{2}$ enrichment, soil N, and water stress on needle surface wax formation in Pinus palustris (Pinaceae). American Journal of Botany, v.84, p.1070-1077, 1997. DOI: $10.2307 / 2446150$.

PRITCHARD, S.G.; AMTHOR, J.S. Crops and environmental change: an introduction to effects of global warming, increasing atmospheric $\mathrm{CO}_{2}$ and $\mathrm{O}_{3}$ concentrations, and soil salinization on crop physiology and yield. Binghampton: Food Products Press, 2005. 421p.

RAMALHO, J.C.; RODRIGUES, A.P.; SEMEDO, J.N.; PAIS, I.P.; MARTINS, L.D.; SIMÕES-COSTA, M.C.; LEITÃO, A.E.; FORTUNATO, A.S.; BATISTA-SANTOS, P.; PALOS, I.M.; TOMAZ, M.A.; SCOTTI-CAMPOS, P.; LIDON, F.C.; DAMATTA, F.M. Sustained photosynthetic performance of Coffea spp. under long-term enhanced $\left[\mathrm{CO}_{2}\right]$. PLoS ONE, v.8, e82712, 2013. DOI: 10.1371/journal.pone.0082712.

RIIKONEN, J.; SYRJÄLÄ, L.; TULVA, I.; MÄND, P.; OKSANEN, E.; POTERI, M.; VAPAAVUORI, E. Stomatal characteristics and infection biology of Pyrenopeziza betulicola in Betula pendula trees grown under elevated $\mathrm{CO}_{2}$ and $\mathrm{O}_{3}$. Environmental Pollution, v.156, p.536-543, 2008. DOI: 10.1016/j.envpol.2008.01.008.

SHEPHERD, T.; GRIFFITHS, D.W. The effects of stress on plant cuticular waxes. New Phytologist, v.171, p.469-499, 2006. DOI: 10.1111/j.1469-8137.2006.01826.x.

STOCKER, T.F.; QIN, D.; PLATTNER, G.-K.; TIGNOR, M.M.B.; ALLEN, S.K.; BOSCHUNG, J.; NAUELS, A.; XIA, Y.; BEX, V.; MIDGLEY, P.M. (Ed.). Climate change 2013: the physical science basis. Cambridge: Cambridge University Press, 2013. 1535p. IPCC.

STURROCK, R.N.; FRANKEL, S.J.; BROWN, A.V.; HENNON, P.E.; KLIEJUNAS, J.T.; LEWIS, K.J.; WORRALL, J.J.; WOODS, A.J. Climate change and forest diseases. Plant Pathology, v.60, p.133-149, 2011. DOI: 10.1111/j.1365-3059.2010.02406.x.

VANHATALO, M.; HUTTUNEN, S.; BÄCK, J. Effects of elevated $\left[\mathrm{CO}_{2}\right]$ and $\mathrm{O}_{3}$ on stomatal and surface wax characteristics in leaves of pubescent birch grown under field conditions. Trees, v.15, p.304-313, 2001. DOI: 10.1007/s004680100105.

ZAMBOLIM, L. Current status and management of coffee leaf rust in Brazil. Tropical Plant Pathology, v.41, p.1-8, 2016. DOI: 10.1007/s40858-016-0065-9.

ZULLO JR., J.; PINTO, H.S.; ASSAD, E.D.; ÁVILA, A.M.H. de. Potential for growing Arabica coffee in the extreme south of Brazil in a warmer world. Climatic Change, v.109, p.535-548, 2011. DOI: $10.1007 / \mathrm{s} 10584-011-0058-0$.

$\overline{\text { Recebido em } 16 \text { de março de } 2016 \text { e aprovado em } 1 \text { de junho de } 2016}$ 